\title{
Estudo comparativo dos métodos diagnósticos para Leishmaniose Visceral em cães oriundos de Ilha Solteira, SP
}

\author{
Comparative study of diagnostic methods for visceral leishmaniasis in dogs from Ilha Solteira, SP \\ Juliana de Assis ${ }^{1 *}$; Nina Marí Gual Pimenta de Queiroz ${ }^{1}$; Rita de Cássia Viveiros da Silveira²; Cáris Maroni Nunes ${ }^{1}$; \\ Trícia Maria Ferreira de Sousa Oliveira ${ }^{3}$; Antonio Carlos Faconti de Noronha Junior'; Maria Francisca Neves²; \\ Rosangela Zacarias Machado ${ }^{3}$; Wilma Aparecida Starke Buzetti ${ }^{2}$
}

${ }^{1}$ Faculdade de Odontologia de Araçatuba, Universidade Estadual Paulista - UNESP

${ }^{2}$ Departamento de Biologia e Zootecnia, Faculdade de Engenharia de Ilha Solteira, Universidade Estadual Paulista - UNESP

${ }^{3}$ Departamento de Patologia Veterinária, Faculdade de Ciências Agrárias e Veterinárias, Universidade Estadual Paulista - UNESP

${ }^{4}$ Centro de Controle de Zoonoses, Ilha Solteira

Recebido em 8 de Setembro de 2009

Aceito em 14 de Outubro de 2009

\section{Resumo}

O objetivo da presente pesquisa foi avaliar comparativamente os métodos diagnósticos da Leishmaniose Visceral Canina (LVC), utilizando-se o ensaio imunoenzimático indireto (ELISA), a reação de imunofluorescência indireta (RIFI), a histoquímica (HE) e a imunoistoquímica (IMIQ) em tecidos de órgãos, como o baço, linfonodo e fígado. Além disso, a Reaçáo em Cadeia pela Polimerase (PCR) das amostras de sangue e dos tecidos foi utilizada para comparar e confirmar os diagnósticos negativos e não conclusivos pelos métodos acima. Para esse estudo, foram utilizados 34 cáes com diferentes sintomas da LVC, classificados em polissintomáticos, oligossintomáticos e assintomáticos e eutanasiados no Centro de Controle de Zoonoses (CCZ) de Ilha Solteira, SP. Os índices de positividade para os testes ELISA, IMIQ, RIFI e HE foram de 65,0, 62,0, 56,0 e 56,0\%, respectivamente, sendo a maior positividade detectada nos cáes polissintomáticos (92,0\%), seguida pelos oligossintomáticos (57,0\%) e assintomáticos (12,5\%). A PCR confirmou os resultados positivos pelas outras técnicas e ainda detectou DNA do parasita nos tecidos de $100 \%$ dos cáes negativos e em $89,0 \%$ dos suspeitos, elevando para $97,0 \%$ a positividade. Em conclusão, a PCR demonstrou ser o método mais sensível e preciso para o diagnóstico definitivo da LVC.

Palavras-chave: Leishmania (L.) chagasi, imunoistoquímica, ELISA, RIFI, PCR.

\begin{abstract}
The purpose of the present work was a comparative study of diagnostic methods for Canine Visceral Leishmaniasis (CVL) using serological methods, enzyme-linked immunosorbent assay (ELISA) and indirect fluorescent antibody test (IFAT), histochemical (HE) and immunohistochemical (IMHC) tests using spleen, lymph node and liver canine tissues. In addition, Polymerase Chain Reaction (PCR) was done in blood and in tissues in order to compare and confirm no conclusive and negative diagnosis by the methods above. For this study, 34 dogs were divided according to clinical signs in asymptomatic, oligosymptomatic and polisymptomatic Leishmania-infected dogs euthanized by Zoonotic Disease Control Center (CCZ) from Ilha Solteira, SP, Brazil. The positivism indexes of ELISA, IMHC, IFAT and $\mathrm{HE}$ were $65.0,62.0,56.0$ and $56.0 \%$, respectively with the highest numbers of positive dogs in polisymptomatic (92.0\%) followed by oligosymptomatic $(57.0 \%)$ and asymptomatic dogs $(12.5 \%)$. Furthermore, PCR confirmed the positive results and detected DNA in tissues from $100 \%$ of negative dogs and $89.0 \%$ suspects raising the animal positivism index up to $97.0 \%$. In conclusion, PCR was the most sensitive and a valuable method for a definitive CVL diagnosis.
\end{abstract}

Keywords: Leishmania (L.) chagasi, immunohistochemistry, ELISA, IFAT, PCR.

\footnotetext{
${ }^{*}$ Autor para correspondência: Juliana de Assis

Programa de Pós-graduaçấo em Ciência Animal,

Curso de Medicina Veterinária Preventiva e Produção Animal,

Universidade Estadual Paulista - UNESP Campus de Araçatuba,

Rua Clóvis Pestana 93, Jardim D. Amélia, CEP 16.050-680, Araçatuba - SP, Brasil

e-mail: jassis_assis@yahoo.com.br

Apoio: sob os auspícios da FAPESP
} 


\section{Introdução}

A Leishmaniose Visceral Canina (LVC) é uma doença causada por protozoários da ordem Kinetoplastida e gênero Leishmania sp (ROSS, 1903). A principal forma de transmissão do parasita para o homem e mamíferos é pela picada do vetor da espécie Lutzomyia (Lutzomyia) longipalpis (SANTA ROSA; OLIVEIRA, 1997). No meio urbano, o cáo é o principal reservatório de parasitas, sendo assim importante na epidemiologia da LVC (DEANE, L. M.; DEANE, M. P., 1955). No Novo Mundo, a LVC é causada pela espécie Leishmania (Leishmania) chagasi (LAINSON; SHAW, 1987).

Os sinais clínicos comuns em cães com LVC são as alterações cutâneas, como pelame seco, prurido, alopecia, áreas de hiperqueratose e nódulos intradérmicos. Também são observados sinais, como apatia, linfoadenomegalia, hepatoesplenomegalia, onicogrifose, emaciação, anemia, além de sinais oculares e emagrecimento (FEITOSA et al., 2000). No entanto, a maioria dos cães infectados não apresenta qualquer sintoma (SIDERIS et al., 1999). Sendo assim, ambos os cães sintomáticos e assintomáticos podem ser igualmente infecciosos para o vetor (MOLINA et al., 1994).

O diagnóstico da LVC está fundamentado nos aspectos clínicos (FEITOSA et al., 2000) e na visualização de formas amastigotas de Leishmania sp em esfregaços de aspirado de baço, medula óssea e linfonodo (SANTA ROSA; OLIVEIRA, 1997; ALVES; BEVILACQUA, 2004). Além disso, atualmente, os testes sorológicos, como o imunoenzimático (ELISA) e a reação de imunofluorescência indireta (RIFI), são recomendados pelo Ministério da Saúde no inquérito epidemiológico canino (BRASIL, 2006), porém apresentam reaçóes cruzadas com Trypanosoma cruzi e L. braziliensis (VEXENAT; SANTANA; TEIXEIRA, 1996).

Recentemente, Oliveira et al. (2008) demonstraram a não reatividade cruzada de soros de cães positivos para $L$. $(L$.) chagasi com antígenos de Ehrlichia canis e de Babesia canis pelo ELISA e RIFI, sendo a coinfecção em cães um achado frequente em áreas endêmicas para a LVC.

Os problemas de resultados falso-negativos pela sorologia podem ainda ser resolvidos por técnicas mais sensíveis, como a imunoistoquímica (FERRER et al., 1988a). Além disso, a técnica de imunoistoquímica tem mostrado ser um competente teste auxiliar para confirmar diagnósticos da LVC, quando comparado à histoquímica, em que os tecidos são apenas corados com hematoxilina e eosina e por isso de difícil visualização de amastigotas nos tecidos (TAFURI et al., 2004).

A técnica molecular, como a reação em cadeia pela polimerase (PCR), tem sido muito utilizada para o diagnóstico da LVC em cães (RODGERS; POPPER; WIRTH, 1990; MANNA et al., 2004; SOLANO-GALLEGO et al., 2004; NUNES et al., 2007). As amostras clínicas biológicas de aspirados ou biópsias de linfonodo, baço, medula óssea e fígado de cão podem ser selecionadas para a detecção do DNA de Leishmania sp pela PCR, mas as amostras de sangue, pele e conjuntiva podem favorecer uma colheita menos invasiva e apresentar melhores resultados (MANNA et al., 2004). No entanto, a PCR, embora de grande sensibilidade, não possui aplicabilidade, ainda, nos programas de controle da LVC. Atualmente, é utilizada em pesquisas e na elucidação de casos inconclusivos da doença, principalmente, em novos focos (GOMES et al., 2007).
Objetivou-se realizar um estudo comparativo de métodos diagnósticos da LVC em cães assintomáticos, oligossintomáticos e polissintomáticos, utilizando-se os exames sorológicos (ELISA e RIFI) em conjunto com os exames parasitológicos, como a coloração histoquímica (HE) e a imunoistoquímica (IMIQ) nos tecidos do baço, linfonodo e fígado. Além disso, objetivou-se também realizar a PCR com o sangue e tecidos do baço, linfonodo e fígado de cães, para comparar e confirmar os diagnósticos inconclusivos e negativos pelos métodos sorológicos e parasitológicos.

\section{Material e Métodos}

\section{Local e cães}

Os cães do presente estudo foram provenientes do município de

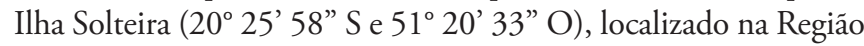
Noroeste do Estado de São Paulo (IBGE, 2007). Foram doados para o presente estudo 34 cães, errantes ou não, naturalmente infectados pela LVC e sorologicamente positivos pela RIFI (ponto de corte $\geq 1: 40$ ). Os animais foram encaminhados ao Centro de Controle de Zoonoses (CCZ) de Ilha Solteira, SP, para serem eutanasiados, em cumprimento ao Decreto $\mathrm{n}^{\circ} .51 .838$ do Ministério da Saúde do Brasil, de 14 de março de 1963, o qual estabelece que animais domésticos portadores de leishmaniose visceral devem ser eutanasiados. No momento da eutanásia e subsequente necropsia, os cães foram examinados quanto aos sintomas e alteraçóes anatomopatológicas e, assim, separados em três grupos: assintomáticos $(\mathrm{n}=8)$; oligossintomáticos, cães que possuíam até três sintomas para LVC $(\mathrm{n}=14)$ e polissintomáticos, cães com mais de três sintomas para LVC $(\mathrm{n}=12)$.

\section{Colheita de amostras}

Antes da eutanásia, o sangue de cada cão foi colhido por punção da veia cefálica, sem e com anticoagulante (EDTA) para obtenção, respectivamente, de sangue total para PCR e soro para a sorologia, armazenados a $-70^{\circ} \mathrm{C}$. Durante a necropsia, foram colhidos fragmentos do baço, fígado e linfonodos (poplíteo, submandibular ou pré-escapular aleatoriamente). Uma parte dos tecidos foi colhida assepticamente e armazenada a $-70{ }^{\circ} \mathrm{C}$ para a extração do DNA; e a outra parte foi fixada em solução neutra tamponada de formol $10 \%$. Os tecidos foram emblocados em parafina e submetidos a cortes em micrótomo a $5 \mu \mathrm{m}$ para a confecção das lâminas.

\section{Testes parasitológicos}

\subsection{Histoquímica (HE)}

Após a confecção das lâminas, todos os tecidos foram hidratados em xilol/álcool e corados com hematoxilina/eosina (HE). Os tecidos foram avaliados conforme a visualização de formas amastigotas de Leishmania sp como: tecido negativo (-), sem amastigotas; tecido suspeito (+/-), quando a coloração não permitiu visualizar claramente os parasitas no tecido; tecidos positivos, quando os 
parasitas foram visualizados dentro ou fora de macrófagos, sendo considerado: tecido fraco positivo (+), quando os parasitas estavam distribuídos esparsamente no tecido; tecido moderado positivo $(++)$, quando os parasitas estavam presentes em torno de $50 \%$ do tecido; e forte positivo $(+++)$, quando os parasitas estavam presentes em uma área superior a 50\% do tecido. Até cinco lâminas de cada tecido foram analisadas.

\subsection{Imunoistoquímica (IMIQ)}

A técnica de IMIQ foi realizada segundo Tafuri et al. (2004), utilizando-se como anticorpo primário o soro hiperimune de um cão naturalmente infectado com $L$. (L.) chagasi (RIFI, título de 1:2560); e como anticorpo secundário o anti-IgG de coelho produzido em cabra. Como modificação da técnica, utilizou-se o anticorpo secundário conjugado à biotina (Vector Laboratories, Inc., Burlingame, CA, USA) ao invés da Peroxidase e o complexo Avidina-Biotina-Peroxidase (Vectstain ABC Kit; Vector Laboratories Inc, Burlingame, CA, USA); e para detecção da reação imunológica, utilizou-se o substrato cromógeno específico para peroxidase (Substrato "New Red" - Vector Laboratories). Os tecidos foram então corados com hematoxilia de Mayer e duas lâminas foram montadas para cada amostra tecidual dos órgáos estudados. O controle negativo foi realizado sem a adição do anticorpo primário ou do secundário. Os parasitas, quando presentes nos tecidos, coraram-se especificamente na cor vermelho-tijolo pela imunorreação.

\section{Testes sorológicos}

\subsection{RIFI}

A técnica RIFI foi realizada segundo a metodologia descrita por Oliveira et. al. (2008). O substrato antigênico foi obtido a partir de promastigotas de $L$. (L.) chagasi cultivadas em meio RPMI - 1640 , a $25^{\circ} \mathrm{C}$. Diluiçóes seriadas de cada soro foram realizadas, iniciando com a diluição de 1:40. O conjugado foi o anti-IgG de cão conjugado ao isotiocianato de fluoresceína (KPL, USA) diluído conforme recomendaçóes do fabricante. Considera-se como soro positivo quando os parasitas apresentam coloração fluorescente em toda a periferia, com ponto de corte $\geq 1: 40$.

\subsection{ELISA}

O teste ELISA indireto foi realizado segundo a técnica preconizada por Machado et al.(1997) e adaptado por Oliveira et al. (2008). Foi utilizado o antígeno solúvel de $L$. (L.) chagasi na concentração de $5 \mu \mathrm{g} \cdot \mathrm{mL}^{-1}$, diluído em tampão carbonato bicarbonato de sódio 0,05 M, pH 9,6. O conjugado anti-cão, IgG de coelho anti-IgG de cão acoplada à fosfatase alcalina (Sigma - Chemical Co) foi diluído a 1:4000 em solução salina tamponada com fosfatos, 0,01 M, pH 7,2 (PBS) adicionado de 0,05\% de Tween-20 (PBS-Tween). Como substrato, utilizou-se o paranitrofenilfosfato diluído a $1 \mathrm{mg} \cdot \mathrm{mL}^{-1}$ em tampão dietanolamina, pH 9,8. A leitura das placas foi realizada em leitor de ELISA (Dynex Technologies. USA) a 405 nm de absorbância.
Os valores de densidade ótica média (DO) foram agrupados em níveis de ELISA (NE), os quais variam de 0 (zero) a 9 (nove), como descrito por Machado et al. (1997). O ponto de corte foi determinado em $\mathrm{NE} \geq 3$, ou seja, todo soro com $\mathrm{NE}$ igual ou maior a 3 é considerado positivo, sendo considerado negativo o soro com NE abaixo de 3 .

A atividade imunológica de cada soro testado foi calculada mediante a determinação do valor A/P (amostra em relação ao positivo), considerando-se os soros de referência negativos e positivos de acordo com a Equação 1, conforme preconizado por Machado et al. (1997)

$$
\begin{aligned}
& \text { Absorbância média - Absorbância média do soro de } \\
& \frac{\mathrm{A}}{\mathrm{P}}=\frac{\text { da amostra }}{\text { Absorbância média do }- \text { Absorbância média do soro de }} \\
& \text { soro de referência positivo referência negativo }
\end{aligned}
$$

Portanto, os níveis de ELISA (NE) definidos estão apresentados abaixo:

$\begin{array}{cc}\mathbf{N E} & \text { Valores de } \mathbf{A} / \mathbf{P} \\ 0 & 0,000-0,146 \\ 1 & 0,147-0,196 \\ 2 & 0,197-0,265 \\ 3 & 0,266-0,358 \\ 4 & 0,359-0,483 \\ 5 & 0,484-0,652 \\ 6 & 0,653-0,881 \\ 7 & 0,882-1,189 \\ 8 & 1,190-1,605 \\ 9 & \geq 1,606\end{array}$

\section{Reação em cadeia pela polimerase (PCR)}

\subsection{Extração do DNA}

De $700 \mu \mathrm{L}$ de sangue foi extraído o DNA, adicionados $800 \mu \mathrm{L}$ de tampáo SSC (3M NaCl, 0,3 citrato de sódio, $\mathrm{pH}=7,0)$ e centrifugado a $8.000 \mathrm{~g}$ por 2 minutos. No material precipitado, adicionou-se $1 \mathrm{~mL}$ de tampão, seguido de agitação e nova centrifugação. Para a lise do precipitado, adicionaram-se $375 \mu \mathrm{L}$ de acetato de sódio $(0,2 \mathrm{M}), 25 \mu \mathrm{L}$ de duodecil sulfato de sódio a $10 \%$ e $5 \mu \mathrm{L}$ de proteinase $\mathrm{K}\left(20 \mathrm{mg} \cdot \mathrm{mL}^{-1}\right)$. Após agitação, a mistura foi incubada a $56^{\circ} \mathrm{C}$ por 2 horas e, em seguida, adicionou-se uma solução de fenol/clorofórmio/álcool isoamílico (25:24:1). Em seguida, o material lisado foi precipitado com álcool etílico absoluto gelado e incubado a $-20{ }^{\circ} \mathrm{C}$ por 30 minutos. Após a incubação, o DNA obtido foi ressuspenso em $100 \mu \mathrm{L}$ de tampão TE (10 mM Tris-base, $1 \mathrm{mM}$ EDTA, $\mathrm{pH} 7,5)$.

O DNA foi extraído dos tecidos do baço, linfonodo e fígado de cães, utilizando-se o Kit QIAamp ${ }^{\oplus}$ DNA Mini Kit (S1306 QIAGEN, USA), para um volume final de $50 \mu \mathrm{L}$, seguindo-se as instruçóes do fabricante.

\subsection{Amplificação de DNA}

Na reação, utilizou-se o par de oligonucleotídeos descrito por Rodgers, Popper e Wirth (1990): 13A 5'-dGTG GGG GAG GGG CGT TCT-3' e 13B 5'-dATT TTA CAC CAA CCC 
CCA GTT-3' para o gênero Leishmania sp, na amplificação de fragmentos de DNA de 120 pares de base (pb), conservados do minicírculo do cinetoplasto. As reaçôes foram constituídas de $1 \mathrm{U}$ de DNA polimerase Platinum ${ }^{\circledast} \mathrm{Taq}$ (Invitrogen), 15,25 $\mu \mathrm{L}$ de água ultrapura, tampão de PCR 1X, 1,5 mM de $\mathrm{MgCl} 2$, 0,31 mM de cada dNTP (dATP, dCTP, dGTP e dTTP), 0,26 $\mu \mathrm{M}$ de Primer "Foward", 0,26 $\mu \mathrm{M}$ de Primer "Reverse" e 2,5 $\mu \mathrm{L}$ de DNA extraído do sangue e dos tecidos. Cada reação foi submetida a 34 ciclos pelo termociclador, sendo que a quantidade de DNA variou de 50 a 300 ng nas reaçóes, num volume final de $25 \mu \mathrm{L}$. Os controles positivos foram DNA de Leishmania extraído do sangue, segundo Nunes et al. (2007), de tecidos do baço, linfonodo e fígado de cáes naturalmente infectados por Leishmania; e os controles negativos foram DNA extraído de sangue, baço, linfonodo e fígado de cães sadios. Os controles das reaçóes para cada tipo de tecido foi uma mistura de $22,5 \mu \mathrm{L}$ de reagentes, sem DNA. Para averiguar os resultados das reaçóes, $8 \mu \mathrm{L}$ dos produtos amplificados foram submetidos à eletroforese, em gel de poliacrilamida a $8 \%$, corados com nitrato de prata e fotografados com câmera digital Cyber-shot de 7.2 Mega pixels, modelo DSC-W70 - SONY.

\section{Análise estatística}

As análises comparativas dos exames diagnósticos foram realizadas pelo Índice Kappa de concordância, para o intervalo de confiança de 95\%, do programa BioEstat (versão 4.0) (AYRES et al., 2005).

\section{Resultados}

\section{Sinais clínicos e anatomopatológicos dos cães}

Dentre os cães estudados, observou-se que, no grupo dos assintomáticos, todos os animais apresentaram aparência saudável. Os cães oligossintomáticos apresentaram até três sintomas ou comprometimento de até três órgãos, sendo os sintomas com maior porcentagem as alteraçóes de pele 10/14 (71,0\%), mucosas pálidas 5/14 (36,0\%) e emagrecimento 2/14 (14,0\%). Já os cães polissintomáticos apresentaram-se com o estado clínico bastante comprometido, com alteraçóes de pele em 12/12 (100\%), esplenomegalia em 10/12 (83,0\%), fígado ictérico em $9 / 12$ (75,0\%), emagrecimento em $7 / 12(58,0 \%)$, linfonodos hipertróficos e onicogrifose em $6 / 12(50,0 \%)$ e ainda alteraçóes oculares e mucosas pálidas em 4/12 (33,0\%).

\section{Exames sorológicos (ELISA e RIFI) e parasitológicos (HE e IMIQ)}

\subsection{Cães assintomáticos}

Na Tabela 1, encontram-se os dados comparativos dos resultados dos testes sorológicos e parasitológicos realizados com os tecidos do baço, linfonodo e fígado dos cães assintomáticos.

Nesse grupo, apenas um cão foi positivo em todos os exames, (cão 19) pois, embora assintomático, esse animal apresentou títulos de anticorpos anti-L. $(L$.) chagasi pelo ELISA (DO = 0,461 e NE $=4)$ e pela RIFI (1:1280) e grau parasitário variando de moderado $(++)$ a intenso positivo $(+++)$ nos tecidos do baço e fígado, respectivamente. Sendo assim, nesse grupo apenas $1 / 8$ $(12,5 \%)$ dos cães foi positivo.

Já os cães $02,04,13$ e 18 foram classificados como suspeitos no estudo. No entanto, dentre esses cães, o cão 04 foi positivo pela imunorreação no linfonodo, e o cão 13 fraco positivo (+) no fígado pela $\mathrm{HE}$, mas permaneceram na classificação de cães suspeitos por apresentarem resultados negativos em ambos os exames sorológicos e com suspeitas de parasitas (+/-) nos demais tecidos pelo método $\mathrm{HE}$. Os cães classificados como negativos foram os cães 01,20 e 22, por apresentarem resultados negativos em todos os exames realizados, correspondendo a 37,5\% (3/8) dos cães assintomáticos.

\subsection{Cães oligossintomáticos}

$\mathrm{Na}$ Tabela 2, encontram-se os dados comparativos dos resultados dos testes sorológicos e parasitológicos realizados com os tecidos do baço, linfonodo e fígado dos cães oligossintomáticos.

Nesse grupo, pelos exames sorológicos, 7/14 (50,0\%) dos cães estavam positivos em ambos os testes (ELISA e RIFI), mas em quatro cães houve discordância entre os exames, ou seja, um cão foi positivo pela RIFI e negativo pelo ELISA e três cães foram positivos pelo ELISA e negativos pela RIFI. Esses três cães negativos somente pela RIFI apresentaram os tecidos do baço, linfonodo e fígado também negativos pela IMIQ e/ou suspeitos pela HE.

Analisando-se os dados da Tabela 2, observou-se que a positividade dos cães nesse grupo foi de 8/14 (57,0\%), mesmo com discordância de resultados entre os exames sorológicos e variação da intensidade parasitária de órgão para órgão entre os cães. $\mathrm{O}$ destaque para os animais positivos foram os cães 07,08 , 12,33 e 34 pela intensa carga parasitária nos tecidos. $\mathrm{O}$ cão 12 foi o que apresentou maior carga parasitária $(++\mathrm{a}+++)$ nos três órgãos examinados, tanto pela $\mathrm{HE}$ como pela IMIQ, além de

Tabela 1. Resultados dos testes sorológicos ELISA e RIFI no sangue, histoquímicos (HE) e imunoistoquímicos (IMIQ), nos tecidos do baço, linfonodo e fígado de cães assintomáticos (A), naturalmente infectados por L. (L.) chagasi, no município de Ilha Solteira, SP

\begin{tabular}{|c|c|c|c|c|c|c|c|c|}
\hline \multirow{4}{*}{$\begin{array}{c}\text { Cães } \\
\text { (A) }\end{array}$} & \multicolumn{8}{|c|}{ Resultados dos Exames dos Animais Assintomáticos } \\
\hline & \multirow{3}{*}{$\begin{array}{c}\text { ELISA } \\
\mathrm{NE}\end{array}$} & \multirow{3}{*}{$\begin{array}{c}\text { RIFI } \\
\text { Diluiçáo }\end{array}$} & \multicolumn{6}{|c|}{ Tecidos } \\
\hline & & & \multicolumn{2}{|c|}{ Baço } & \multicolumn{2}{|c|}{ Linfonodo } & \multicolumn{2}{|c|}{ Fígado } \\
\hline & & & HE & IMIQ & HE & IMIQ & HE & IMIQ \\
\hline 01 & $\mathrm{~N}$ & $\mathrm{~N}$ & - & $\mathrm{N}$ & - & $\mathrm{N}$ & - & $\mathrm{N}$ \\
\hline 02 & $\mathrm{~N}$ & $\mathrm{~N}$ & $+/-$ & NR & - & NR & $+1-$ & $\mathrm{N}$ \\
\hline 04 & $\mathrm{~N}$ & $\mathrm{~N}$ & $+1-$ & $\mathrm{N}$ & $+1-$ & $\mathrm{P}$ & $+1-$ & $\mathrm{N}$ \\
\hline 13 & $\mathrm{~N}$ & $\mathrm{~N}$ & $+1-$ & $\mathrm{N}$ & $+1-$ & $\mathrm{N}$ & + & $\mathrm{N}$ \\
\hline 18 & $\mathrm{~N}$ & $\mathrm{~N}$ & $+1-$ & $\mathrm{N}$ & $+1-$ & $\mathrm{N}$ & $+1-$ & $\mathrm{N}$ \\
\hline 19 & 4 & $1: 1280$ & +++ & P & $+1-$ & $\mathrm{P}$ & ++ & $\mathrm{P}$ \\
\hline 20 & $\mathrm{~N}$ & $\mathrm{~N}$ & - & $\mathrm{N}$ & - & $\mathrm{N}$ & - & $\mathrm{N}$ \\
\hline 22 & $\mathrm{~N}$ & $\mathrm{~N}$ & - & $\mathrm{N}$ & - & $\mathrm{N}$ & - & $\mathrm{N}$ \\
\hline
\end{tabular}

P: Positivo; N: Negativo; NR: Não Realizado; NE: Nível de ELISA; -: tecido negativo; +/-: tecido suspeito; +: tecido fraco positivo; ++: tecido moderado positivo; +++: tecido forte positivo. 
Tabela 2. Resultados dos testes sorológicos ELISA e RIFI no sangue, histoquímicos (HE) e imunoistoquímicos (IMIQ) nos tecidos do baço, linfonodo e fígado de cães oligossintomáticos $(\mathrm{O})$, naturalmente infectados por L. (L.) chagasi, no município de Ilha Solteira, SP

\begin{tabular}{|c|c|c|c|c|c|c|c|c|}
\hline \multirow{4}{*}{$\begin{array}{l}\text { Cáes } \\
\text { (O) }\end{array}$} & \multicolumn{8}{|c|}{ Resultados dos Exames dos Animais Oligossintomáticos } \\
\hline & \multirow{3}{*}{$\begin{array}{c}\text { ELISA } \\
\text { NE }\end{array}$} & \multirow{3}{*}{$\begin{array}{c}\text { RIFI } \\
\text { Diluição }\end{array}$} & \multicolumn{6}{|c|}{ Tecidos } \\
\hline & & & \multicolumn{2}{|c|}{ Baço } & \multicolumn{2}{|c|}{ Linfonodo } & \multicolumn{2}{|c|}{ Fígado } \\
\hline & & & HE & IMIQ & HE & IMIQ & HE & IMIQ \\
\hline 03 & 4 & $1: 2560$ & NR & NR & ++ & $\mathrm{P}$ & $+/-$ & $\mathrm{P}$ \\
\hline 06 & 4 & $\mathrm{~N}$ & $+/-$ & $\mathrm{N}$ & $+1-$ & $\mathrm{N}$ & - & $\mathrm{N}$ \\
\hline 07 & 5 & $1: 1280$ & + & $\mathrm{P}$ & + & $\mathrm{P}$ & + & P \\
\hline 08 & 6 & $1: 1280$ & + & $\mathrm{P}$ & + & NR & $+/-$ & $\mathrm{P}$ \\
\hline 09 & 4 & $\mathrm{~N}$ & $+1-$ & $\mathrm{N}$ & $+1-$ & $\mathrm{N}$ & - & $\mathrm{N}$ \\
\hline 10 & 4 & $1: 640$ & - & $\mathrm{P}$ & $+1-$ & $\mathrm{N}$ & - & $\mathrm{P}$ \\
\hline 11 & $\mathrm{~N}$ & $\mathrm{~N}$ & - & $\mathrm{N}$ & - & $\mathrm{N}$ & - & $\mathrm{N}$ \\
\hline 12 & 6 & $1: 1280$ & +++ & $\mathrm{P}$ & +++ & $\mathrm{P}$ & ++ & $\mathrm{P}$ \\
\hline 14 & $\mathrm{~N}$ & $\mathrm{~N}$ & $+1-$ & $\mathrm{N}$ & $+1-$ & $\mathrm{N}$ & $+1-$ & $\mathrm{N}$ \\
\hline 15 & 4 & $1: 320$ & + & $\mathrm{P}$ & + & P & $+1-$ & P \\
\hline 21 & 4 & $\mathrm{~N}$ & $+1-$ & $\mathrm{N}$ & $+1-$ & $\mathrm{N}$ & - & $\mathrm{N}$ \\
\hline 23 & $\mathrm{~N}$ & $\mathrm{~N}$ & - & $\mathrm{N}$ & - & $\mathrm{N}$ & - & $\mathrm{N}$ \\
\hline 33 & $\mathrm{~N}$ & $1: 320$ & +++ & P & $+1-$ & $\mathrm{N}$ & $+1-$ & $\mathrm{P}$ \\
\hline 34 & 5 & $1: 640$ & ++ & $\mathrm{N}$ & ++ & $\mathrm{P}$ & $+1-$ & $\mathrm{N}$ \\
\hline
\end{tabular}

P: Positivo; N: Negativo; NR: Não Realizado; NE: Nível de ELISA; -: tecido negativo; +/-: tecido suspeito; +: tecido fraco positivo; ++: tecido moderado positivo; +++: tecido forte positivo.

apresentar altos títulos de anticorpos no ELISA $(\mathrm{NE}=6)$ e na RIFI (1:1280).

Dentre os animais desse grupo, $4 / 14(28,5 \%)$ dos cães foram classificados como suspeitos (cães 06, 09, 14 e 21), pois além de ter ocorrido discordância entre os exames sorológicos, apresentaram tecidos (+/-) e (-) pela HE e foram negativos pela IMIQ. Além disso, apenas $2 / 14(14,3 \%)$ dos cães foram considerados negativos em todas as provas sorológicas e parasitológicas realizadas (cães 11 e 23) (Tabela 2).

\subsection{Cães polissintomáticos}

$\mathrm{Na}$ Tabela 3, encontram-se os dados comparativos dos resultados dos testes sorológicos e parasitológicos realizados com os tecidos do baço, linfonodo e fígado dos cães polissintomáticos.

A positividade para LVC nesse grupo foi de 11/12 (92,0\%) dos cães. Na maioria dos animais, observou-se predomínio de moderado a intenso $(++\mathrm{a}+++)$ parasitismo nos tecidos hepáticos, esplênicos e nos linfonodos, mesmo havendo discordância entre a RIFI e ELISA, particularmente nos cáes 05 e 31 (Tabela 3).

Embora com vários sintomas característicos para LVC, o cão 28 foi negativo nos exames sorológicos e na maioria dos tecidos suspeitos $(+/-)$ pela técnica HE e negativo (-) pela IMIQ. Sendo assim, foi o único cão polissintomático classificado como suspeito.

Dentre os tecidos analisados, o baço e o linfonodo foram os mais parasitados pela técnica HE na maioria dos cães, além de serem também positivos na IMIQ, seguidos pelo fígado, em que
Tabela 3. Resultados dos testes sorológicos ELISA e RIFI no sangue, histoquímicos (HE) e imunoistoquímicos (IMIQ) nos tecidos do baço, linfonodo e fígado de cães polissintomáticos $(\mathrm{P})$, naturalmente infectados por $L$. $(L$.$) chagasi, no município de Ilha Solteira, SP$

\begin{tabular}{|c|c|c|c|c|c|c|c|c|}
\hline \multirow{4}{*}{$\begin{array}{c}\text { Cães } \\
\text { (P) }\end{array}$} & \multicolumn{8}{|c|}{ Resultados dos Exames dos Animais Polissintomáticos } \\
\hline & \multirow{3}{*}{$\begin{array}{c}\text { ELISA } \\
\mathrm{NE}\end{array}$} & \multirow{3}{*}{$\begin{array}{c}\text { RIFI } \\
\text { Diluiçáo }\end{array}$} & \multicolumn{6}{|c|}{ Tecidos } \\
\hline & & & \multicolumn{2}{|c|}{ Baço } & \multicolumn{2}{|c|}{ Linfonodo } & \multicolumn{2}{|c|}{ Fígado } \\
\hline & & & HE & IMIQ & HE & IMIQ & HE & IMIQ \\
\hline 05 & $\mathrm{~N}$ & $1: 160$ & ++ & $\mathrm{P}$ & + & $\mathrm{P}$ & + & $\mathrm{P}$ \\
\hline 16 & 6 & $1: 1280$ & $+1-$ & $\mathrm{P}$ & ++ & $\mathrm{P}$ & - & $\mathrm{P}$ \\
\hline 17 & 5 & $1: 1280$ & $+1-$ & $\mathrm{N}$ & $+1-$ & $\mathrm{N}$ & ++ & $\mathrm{P}$ \\
\hline 24 & 6 & $1: 1280$ & + & $\mathrm{P}$ & + & $\mathrm{N}$ & $+1-$ & $\mathrm{P}$ \\
\hline 25 & 6 & $1: 1280$ & +++ & $\mathrm{P}$ & ++ & $\mathrm{P}$ & + & $\mathrm{P}$ \\
\hline 26 & 5 & $1: 1280$ & + & $\mathrm{P}$ & + & $\mathrm{P}$ & +++ & $\mathrm{P}$ \\
\hline 27 & 5 & $1: 1280$ & +++ & $\mathrm{P}$ & +++ & $\mathrm{P}$ & +++ & $\mathrm{P}$ \\
\hline 28 & $\mathrm{~N}$ & $\mathrm{~N}$ & $+1-$ & $\mathrm{N}$ & $+1-$ & $\mathrm{N}$ & $+1-$ & $\mathrm{N}$ \\
\hline 29 & 6 & $1: 1280$ & + & $\mathrm{P}$ & ++ & $\mathrm{P}$ & $+1-$ & $\mathrm{P}$ \\
\hline 30 & 4 & $1: 2560$ & +++ & $\mathrm{P}$ & +++ & $\mathrm{P}$ & - & $\mathrm{P}$ \\
\hline 31 & 6 & $\mathrm{~N}$ & ++ & $\mathrm{P}$ & +++ & $\mathrm{P}$ & ++ & $\mathrm{P}$ \\
\hline 32 & 5 & $1: 1280$ & +++ & $\mathrm{P}$ & +++ & $\mathrm{P}$ & $+1-$ & $\mathrm{P}$ \\
\hline
\end{tabular}

P: Positivo; N: Negativo; NR: Não Realizado; NE: Nível de ELISA; -: tecido negativo; +/-: tecido suspeito; +: tecido fraco positivo; ++: tecido moderado positivo; +++: tecido forte positivo.

o grau parasitário de alguns animais foi muito baixo (+/-) pela HE, embora positivo na IMIQ. No entanto, em outros animais, como os cães 26,27 e 31, o grau parasitário no fígado foi tão alto quanto o observado no baço e no linfonodo da maioria dos cáes polissintomáticos (Tabela 3).

\section{Reação em cadeia pela polimerase (PCR)}

Pelos métodos sorológicos (RIFI e ELISA) e parasitológicos (HE e IMIQ), 20/34 (60,0\%) dos cães estavam positivos, mas $9 / 34(26,0 \%)$ permaneceram ainda como suspeitos e 5/34 (14,0\%) negativos (Figura 1). Os casos suspeitos e os diagnósticos negativos, tiveram as amostras testadas pela PCR utilizando o sangue e os tecidos hepáticos, esplênicos e linfonodos dos cáes. A PCR diagnosticou como positivo o cão que apresentou pelo menos um órgão (linfonodo, baço ou fígado) ou o sangue positivo e, como negativo, quando todos os tecidos e o sangue estavam negativos. Para os 14 cães suspeitos ou negativos, a PCR revelou-se positiva em quase todos os cães 13/14 (93,0\%), com exceção apenas do câo 21. Nos demais animais diagnosticados como negativos, pelas provas sorológicas e parasitologias, a PCR foi positiva (Tabela 4), elevando a positividade do diagnóstico dos cáes com LVC para 33/34 (97,0\%), elucidando os casos suspeitos e negativos das amostras de tecidos do sangue.

Em sequência, os testes ELISA, IMIQ, RIFI e HE apresentaram positividades de $65,0,62,0,56,0$ e $56,0 \%$, respectivamente (Figura 2). 


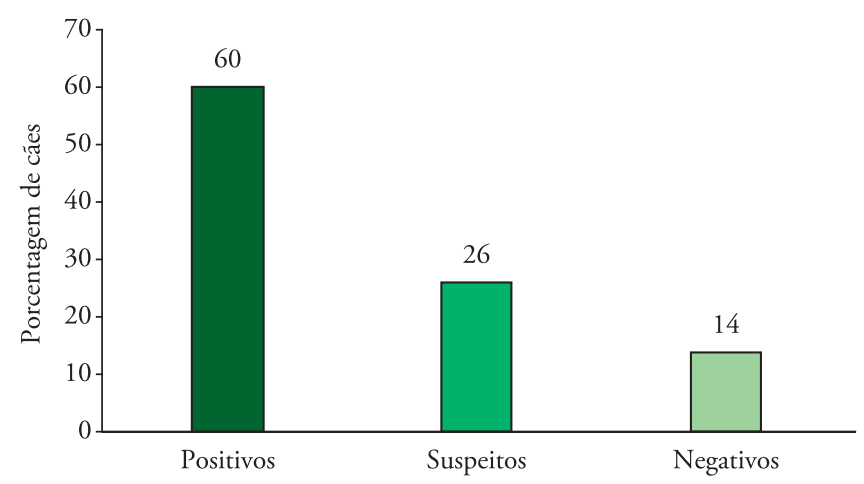

Figura 1. Porcentagem (\%) de cães positivos, suspeitos e negativos para LVC pelos resultados dos testes sorológicos (RIFI e ELISA) e parasitológicos (HE e IMIQ).

Tabela 4. Resultados da PCR realizada nos tecidos do baço, linfonodo, fígado e no sangue dos cáes considerados suspeitos e negativos pelos testes ELISA indireto, RIFI, histoquímico (HE) e imunoistoquímico (IMIQ).

\begin{tabular}{ccccc}
\hline \multirow{2}{*}{ Cáes } & \multicolumn{3}{c}{ Resultados da PCR } \\
\cline { 2 - 3 } & \multicolumn{3}{c}{ Tecidos } & Sangue \\
\cline { 2 - 4 } Suspeitos & Baço & Linfonodo & Fígado & \\
2 & & & $\mathrm{P}$ & $\mathrm{P}$ \\
4 & $\mathrm{P}$ & $\mathrm{P}$ & $\mathrm{P}$ & $\mathrm{P}$ \\
6 & $\mathrm{P}$ & $\mathrm{P}$ & $\mathrm{P}$ & $\mathrm{P}$ \\
9 & $\mathrm{~N}$ & $\mathrm{~N}$ & $\mathrm{~N}$ & $\mathrm{~N}$ \\
13 & $\mathrm{P}$ & $\mathrm{P}$ & $\mathrm{P}$ & $\mathrm{P}$ \\
14 & $\mathrm{~N}$ & $\mathrm{P}$ & $\mathrm{N}$ & $\mathrm{N}$ \\
18 & $\mathrm{P}$ & $\mathrm{P}$ & $\mathrm{P}$ & $\mathrm{P}$ \\
21 & $\mathrm{P}$ & $\mathrm{P}$ & $\mathrm{P}$ & $\mathrm{N}$ \\
28 & $\mathrm{~N}$ & $\mathrm{~N}$ & $\mathrm{~N}$ & $\mathrm{P}$ \\
Negativos & $\mathrm{P}$ & $\mathrm{P}$ & $\mathrm{P}$ & \\
1 & & & & $\mathrm{P}$ \\
11 & $\mathrm{P}$ & $\mathrm{P}$ & $\mathrm{P}$ & $\mathrm{P}$ \\
20 & $\mathrm{P}$ & $\mathrm{P}$ & $\mathrm{P}$ & $\mathrm{P}$ \\
22 & $\mathrm{P}$ & $\mathrm{N}$ & $\mathrm{P}$ & $\mathrm{P}$ \\
23 & $\mathrm{P}$ & $\mathrm{N}$ & $\mathrm{P}$ & $\mathrm{P}$ \\
\hline $\mathrm{P}$ & $\mathrm{P}$ & $\mathrm{P}$ & & $\mathrm{P}$ \\
\hline
\end{tabular}

P: Positivo; N: Negativo

\section{Comparação de testes diagnósticos}

Os resultados da comparação, analisados dois a dois, entre o método IMIQ, os métodos sorológicos (RIFI e ELISA) e o molecular (PCR), estáo apresentados nas Tabelas 5, 6 e 7, respectivamente. Além disso, essa análise foi também realizada, comparando-se os métodos sorológicos (RIFI e ELISA) com a PCR (Tabela 8). Os resultados da porcentagem de concordância, coeficiente Kappa e valor de p estão também ilustrados em cada tabela.

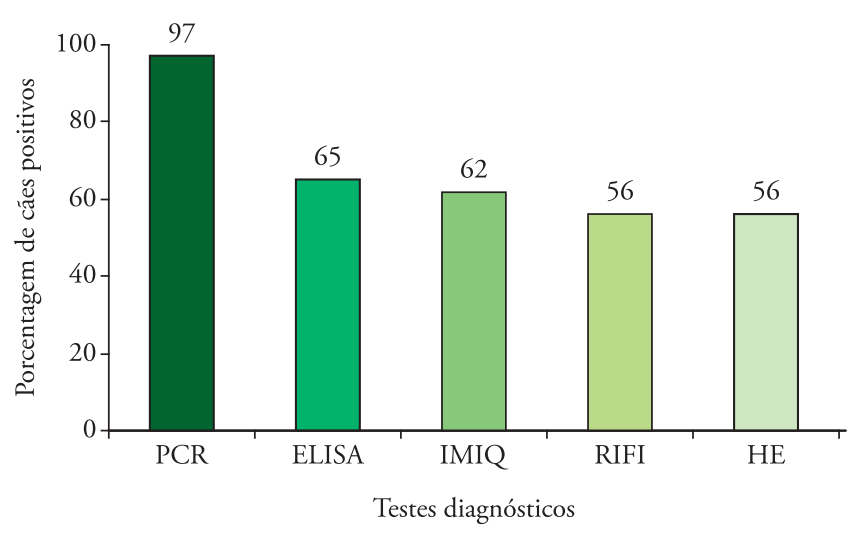

Figura 2. Porcentagens (\%) de cães positivos para LVC pelos testes PCR, ELISA, IMIQ, RIFI e HE.

Tabela 5. Resultados do teste IMIQ no tecido do baço comparado aos testes RIFI, ELISA e PCR realizados com o sangue dos cães comparados pelo teste Kappa

\begin{tabular}{lccc}
\hline \multirow{2}{*}{$\begin{array}{c}\text { Baço } \\
(\mathbf{n}=\mathbf{3 2})\end{array}$} & \multicolumn{3}{c}{ Testes de Diagnósticos } \\
\cline { 2 - 4 } \multicolumn{1}{c}{ IMIQ $\times$ RIFI } & IMIQ $\times$ ELISA & IMIQ $\times \mathbf{P C R}$ \\
\hline Kappordância $(\%)$ & 91,0 & 78,0 & 62,5 \\
$\mathrm{p}$ & 0,8110 & 0,5556 & 0,2099 \\
$\mathrm{p} \leq 0,05^{*}$ & $<0,0001^{*}$ & $0,0007^{*}$ & $0,0264^{*}$ \\
\hline
\end{tabular}

Tabela 6. Resultados do teste IMIQ no tecido do linfonodo comparado aos testes RIFI, ELISA e PCR realizados com o sangue dos cáes comparados pelo teste Kappa

\begin{tabular}{lccc}
\hline \multicolumn{1}{c}{$\begin{array}{c}\text { Linfonodo } \\
(\mathbf{n}=\mathbf{3 2})\end{array}$} & \multicolumn{3}{c}{ Testes de Diagnósticos } \\
\cline { 2 - 4 } & IMIQ $\times$ RIFI & IMIQ $\times$ ELISA & IMIQ $\times$ PCR \\
\hline Concordância $(\%)$ & 78,0 & 75,0 & 59,0 \\
Kappa & 0,6141 & 0,5000 & 0,1875 \\
$\mathrm{p}$ & $0,0003^{*}$ & $0,0017^{*}$ & $0,0344^{*}$ \\
\hline
\end{tabular}

$\mathrm{p} \leq 0,05^{*}$

Tabela 7. Resultados do teste IMIQ no tecido do fígado comparado aos testes RIFI, ELISA e PCR realizados com o sangue dos cães comparados pelo teste Kappa

\begin{tabular}{lccc}
\hline \multirow{2}{*}{ Fígado $(\mathbf{n}=34)$} & \multicolumn{3}{c}{ Testes de Diagnósticos } \\
\cline { 2 - 4 } & IMIQ $\times$ RIFI & IMIQ $\times$ ELISA & IMIQ $\times$ PCR \\
\hline Concordância (\%) & 94,0 & 82,0 & 65,0 \\
Kappa & 0,8887 & 0,6370 & 0,2184 \\
$\mathrm{p}$ & $<0,0001^{*}$ & $<0,0001^{*}$ & $0,0206^{*}$ \\
\hline $\mathrm{p} \leq 0,05^{*}$ & \multicolumn{3}{l}{}
\end{tabular}

Tabela 8. Resultados dos testes RIFI, ELISA e PCR realizados com o sangue dos cães comparados entre si pelo teste Kappa

\begin{tabular}{lccc}
\hline Sangue $(\mathbf{n}=34)$ & \multicolumn{3}{c}{ Testes de Diagnósticos } \\
\cline { 2 - 4 } & ELISA $\times$ RIFI & PCR $\times$ RIFI & ELISA $\times$ PCR \\
\hline Concordância (\%) & 82,0 & 65,0 & 59,0 \\
Kappa & 0,6370 & 0,2184 & $-0,0215$ \\
$\mathrm{p}$ & $<0,0001^{*}$ & $0,0206^{*}$ & 0,4274 \\
\hline
\end{tabular}

$\mathrm{p} \leq 0,05^{*}$ 


\section{Discussáo}

De acordo com Sideris et al. (1999), muitos cáes infectados pela LVC podem náo apresentar nenhum sintoma e permanecer aparentemente saudáveis por toda a vida, desenvolvendo uma adequada resposta imune celular, tornando-se resistentes à doença (PINELLI et al., 1994). Na presente pesquisa, 8/34 (23,5\%) dos cães eram assintomáticos e, dentre esses, apenas um cão (12,5\%) estava soropositivo e com os tecidos do baço, linfonodo e fígado intensamente parasitados (positivos pela HE e IMIQ). No entanto, pela PCR, identificou-se $100 \%$ dos cáes assintomáticos como positivos para LVC, embora sem a identificação de formas amastigotas íntegras nos tecidos, com exceção do cão 19, o único cão positivo nesse grupo.

O maior grupo, neste estudo, foi o oligossintomático com 14/34 $(41,0 \%)$ dos cães. Nesse grupo, havia $50,0 \%$ dos cáes positivos pelos métodos sorológicos ELISA e RIFI, embora com discordância entre esses dois testes de $28,5 \%$, além de haver também $21,4 \%$ de cães negativos em ambos os testes. Os cães oligossintomáticos apresentaram até três sintomas de LVC, que incluíam alteraçôes gerais de pele, emagrecimento e a presença de mucosas pálidas, como os mais comuns. No entanto, esses sintomas poderiam ser confundidos com os sintomas de outras enfermidades de origem parasitária, dificultando a interpretaçáo dos resultados diagnósticos. As infecçôes simultâneas com doença de Chagas, leishmaniose tegumentar (COUTINHO et al., 1985; COSTA et al., 1991; FERREIRA et al., 2007) e erlichiose (FERREIRA et al., 2007) foram observadas simultaneamente em muitos cães com LVC. A possível constatação de reaçôes cruzadas, em testes sorológicos, fez com que alguns autores sugerissem cautela nas campanhas de saúde pública, em relação à prevalência da LVC (COSTA et al., 1991), principalmente nos cães oligossintomáticos. No entanto, no presente estudo, apenas um cáo oligossintomático (cão 21) apresentou resultado negativo pela PCR. Esse resultado elevou a positividade do grupo para $93,0 \%$ e reforçou a necessidade da associação de métodos para o diagnóstico da doença. Vale ressaltar que a coinfecção entre $L$. (L.) chagasi, E. canis e B. canis existe; entretanto, não foi demonstrado reatividade cruzada entre os antígenos, em soros de cães com LVC pelas técnicas ELISA e RIFI (OLIVEIRA et al., 2008).

Já, com relação ao grupo polissintomático, 91,6\% dos cáes estavam positivos para LVC pelos exames sorológicos e parasitológicos, além de apresentarem grau bastante avançado da doença e com diversas manifestaçôes clínicas. Notou-se, ainda, a presença de várias alteraçóes cutâneas em 100\% dos cães examinados. As alteraçôes cutâneas são bem frequentes em animais com LVC, as quais aparecem de acordo com a resposta imune do cáo ou de vigência com outras enfermidades (FERRER et al., 1988b). Além disso, 83,0 e 50,0\%, dos cães apresentaram esplenomegalia e linfoadenomegalia, respectivamente. Em concordância com os resultados obtidos por Ciaramella et al. (1997), verificou-se que o comprometimento do baço é comum em cães sintomáticos para LVC. Outro órgão comprometido foi o fígado que se apresentou ictérico, com manchas brancas e hepatomegalia, além de apresentar granulomas. Concordante com o presente estudo, Noli (1999) verificou que os parasitas desenvolvem-se nos tecidos hepáticos no interior de macrófagos, levando às alteraçóes inflamatórias. As demais alteraçóes observadas, como emagrecimento, onicogrifose, alteraçóes oculares e mucosas pálidas caracterizaram a presença da LVC nos cães.

Por outro lado, o diagnóstico foi mais fácil nos cães polissintomáticos em razão da positividade desses animais em todos os testes realizados, com grau parasitário bastante intenso, particularmente nos tecidos do baço e linfonodo e níveis de anticorpos pelos testes ELISA (NE = 4 a 6) e RIFI (1:1280). Nesse grupo, observou-se um cáo negativo nas provas sorológicas e imunoistoquímicas e suspeito na técnica histoquímica, além de apresentar alteraçóes cutâneas generalizadas por todo o corpo. Como o animal havia sido submetido ao tratamento contra sarna pelos proprietários, provavelmente pode ter interferido no resultado do diagnóstico da LVC. No entanto, esse cão apresentou resultado positivo na PCR realizada com amostras teciduais de todos os órgãos e amostra de sangue.

As características das técnicas diagnósticas são parâmetros importantes na escolha do teste a ser utilizado num programa de controle da LVC, principalmente quando a eliminação do cão positivo é uma das medidas adotadas (ALVES; BEVILACQUA, 2004). Os testes RIFI e ELISA são geralmente utilizados na detecção de anticorpos anti-Leishmania em soros de cães, porém observa-se ocorrência de reaçôes cruzadas nesses testes (COUTINHO et al., 1985; VEXENAT; SANTANA; TEIXEIRA, 1996; OLIVEIRA et al., 2008). A divergência de resultados entre exames sorológicos, possivelmente, ocorre em consequência dos diferentes protocolos utilizados (METTLER et al., 2005; ROSÁRIO et al., 2005). Além disso, no presente trabalho, os testes ELISA e RIFI apresentaram, respectivamente, as positividades de 71,0 e $57,0 \%$ nos cáes oligossintomáticos; e de 12,5 e $83,0 \%$ para ambos os testes sorológicos (sem discordância entre eles), nos cães assintomáticos e polissintomáticos, respectivamente.

O ELISA teste apresentou uma positividade de $65,0 \%$, seguido pela IMIQ (62,0\%), RIFI e HE (56,0\%). No geral, quando os testes sorológicos apresentavam altos títulos de anticorpos anti- $L$. (L.) chagasi, os tecidos também se encontravam fortemente parasitados, principalmente nos cães polissintomáticos. Assim, $85,0 \%$ dos tecidos com grau parasitário que variavam de duas a três cruzes pela HE e positivos pela IMIQ, pertenciam aos cáes com altos títulos de anticorpos. Isso significa que a resposta humoral, com alta produção de anticorpos, não protegeu os animais dessa infecção parasitária. Para os cáes que desenvolvem a LVC de forma severa e progressiva, a doença está associada com uma resposta do tipo Th2, predominantemente imune-humoral, sendo incapazes de conter a infecção (PINELLI et al., 1994). Concordante com o presente resultado, outros autores têm demonstrado altos títulos de anticorpos e intensa carga parasitária em tecidos do baço, fígado, linfonodo, pele e medula óssea em cáes polissintomáticos, comparados aos cáes assintomáticos com baixos níveis de anticorpos e graus parasitários (REIS et al., 2006; TASCA et al., 2009).

No entanto, diferentemente dos outros câes assintomáticos, um câo apresentou uma elevada produçáo de anticorpos anti- $L$. (L.) chagasi, além de forte e moderado parasitismo no baço e fígado, respectivamente, pela HE. Esse resultado poderia indicar que esse cão estaria no início da infecção (PINELLI et al., 1994) ou ainda em equilíbrio na interação hospedeiro-parasita 
(OLIVEIRA; SANTORO; SADIGURSKY, 1993), o que favoreceu o encontro de grande número de parasitas intactos nos tecidos.

Segundo Madeira et al. (2006), o maior obstáculo para a interpretação dos dados sorológicos é a ausência de informaçôes parasitológicas. Assim, no presente trabalho, realizaram-se estudos paralelos com os métodos parasitológicos HE e IMIQ para auxiliar a interpretação dos resultados dos testes ELISA e RIFI. O método IMIQ, de visualização direta dos parasitas nos tecidos, é muito importante por causa da sua maior especificidade em relação ao HE; no entanto, oferece ainda dificuldade nos cáes assintomáticos, nos quais há poucos parasitas nos tecidos, dificultando o diagnóstico (FERRER et al., 1988a; TAFURI et al., 2004). Dessa forma, para aqueles cães com dúvidas na identificação das formas amastigotas pela técnica da $\mathrm{HE}$, classificados na categoria de suspeitos, estes seriam confirmados posteriormente pela técnica IMIQ, com a vantagem de maior contraste entre o parasita e os tecidos dos cáes, e melhor visualização das formas amastigotas (TAFURI et al., 2004; TASCA et al., 2009).

A técnica IMIQ, comprovou a positividade dos tecidos pela $\mathrm{HE}$, e os casos suspeitos e negativos foram elucidados com detecção dos parasitas de 62,0 e $56,0 \%$, respectivamente, nos três órgãos analisados.

A discordância de resultados entre o ELISA, RIFI e a não detecçáo de amastigotas em tecidos de alguns animais, leva-nos a utilizar outra técnica mais sensível. A PCR tem demonstrado ser uma técnica altamente sensível para o diagnóstico clínico da LVC em cáes por ser capaz de amplificar o kDNA de Leishmania sp. a partir de poucos exemplares de amastigotas presentes na amostra (RODGERS; POPPER; WIRTH, 1990; MANNA et al., 2004; SOLANO-GALLEGO et al., 2004; NUNES et al., 2007). Além disso, Solano-Gallego et al. (2004) mostraram que os cães assintomáticos e negativos na IMIQ foram positivos na PCR para Leishmania sp, indicando que o baixo número de parasitas nos tecidos dificultava a identificaçáo, mesmo quando foram empregadas técnicas tão sensíveis como a IMIQ. A positividade pela PCR, realizada com o sangue dos 34 cães, elevou o percentual de positivos para $91,0 \%$. Em pesquisa realizada com 95 cães com LVC, na Itália, Manna et al. (2004) verificaram uma positividade do sangue pela PCR de $94,0 \%$, bem próximo dos dados obtidos neste trabalho, além da sensibilidade dessa técnica ser de $100 \%$. Neste trabalho, a PCR confirmou os resultados positivos pelas outras técnicas e ainda detectou DNA do parasita em 93,0\% dos cães com diagnósticos inconclusivos, ou seja, em $100 \%$ de cães negativos e em $89,0 \%$ dos suspeitos. Apenas um dentre os 34 cães estudados, nessa pesquisa, realmente encontrava-se negativo para LVC pela PCR e pelos exames parasitológicos (HE e IMIQ), elevando para $97,0 \%$ a positividade dos cáes. Como Ilha Solteira pertence a uma área considerada endêmica para LVC, não foi surpresa observar a alta positividade dos cães analisados pela PCR.

Por ser o teste IMIQ bastante específico (FERRER et al., 1988a; TAFURI et al., 2004) e de fácil visualização das formas amastigotas intactas nos tecidos, a análise comparativa entre o IMIQ e os outros testes mostraram melhores resultados para o IMIQ e a RIFI tanto no baço (Kappa $=0,8110)$ como no fígado $($ Kappa $=0,8887)$ e linfonodo $($ Kappa $=0,6141)$. Além disso, foi evidente a alta concordância (78\% a 94\%) entre os testes para a detecção de anticorpos, tanto no soro como em tecidos de cães, mesmo sendo amostras biológicas diferentes. Por outro lado, o nível de concordância entre o ELISA versus IMIQ $($ Kappa = 0,6370) nos tecidos foi boa (Kappa variando de 0,50 a 0,64). Semelhante a esse valor foi o coeficiente Kappa observado na comparação do ELISA versus RIFI com uma concordância boa.

O resultado da PCR realizada com amostras sanguíneas de todos os cáes foi também comparado (dois a dois) com a RIFI, ELISA e IMIQ para os três órgãos, e as análises comparativas revelaram baixa concordância entre a PCR e os demais exames, com porcentagens variando de 59,0 a 65,0\% e valores baixos dos coeficientes Kappa, ou seja, variando de 0,4274 a 0,0206. Essas discordâncias podem ser explicadas pela alta positividade apresentada pela PCR no sangue em comparaçấo aos demais testes no presente trabalho. No entanto, o método PCR deve ser analisado com cautela nas campanhas epidemiológicas, pois detecta apenas o DNA do parasita no sangue e tecidos dos cáes e não necessariamente a doença no animal, diferentemente do exame parasitológico que detecta o parasita intacto nos tecidos.

Em conclusão, os índices de positividade dos métodos PCR, ELISA, IMIQ, RIFI e HE foram de 97,0, 65,0, 62,0, 56,0 e $56,0 \%$, respectivamente. No entanto, os resultados da presente pesquisa revelaram que nenhuma prova diagnóstica, quando testada isoladamente, identificou adequadamente os cães com LVC, sendo a PCR o método que apresentou maior positividade para o diagnóstico definitivo, quando os testes parasitológicos e sorológicos não foram capazes de detectar cáes positivos para LVC.

\section{Agradecimentos}

Os autores agradecem à FAPESP pelo apoio financeiro e ao Centro de Controle de Zoonoses de Ilha Solteira, SP pela doação dos animais.

\section{Referências}

ALVES, W. A.; BEVILACQUA, P. D. Reflexóes sobre a qualidade do diagnóstico da leishmaniose visceral canina em inquéritos epidemiológicos: o caso da epidemia de Belo Horizonte, Minas Gerais, Brasil, 1993-1997. Caderno de Saúde Pública, v. 20, n. 1, p. 259-265, 2004.

AYRES, M. et al. BioEstat: aplicaçóes estatísticas nas áreas das ciências bio-médicas. Versão 4.0. Belém: Instituto de desenvolvimento sustentável Mamirauá, 2005.

BRASIL. MINISTÉRIO DA SAÚDE. Manual de vigilância e controle da Leishmaniose Visceral Americana do Estado de Sáo Paulo: normas e manuais técnicos. Brasília, 2006. 160 p. (Série A)

CIARAMELLA, P. et al. A retrospective clinical study of canine leishmaniasis in 150 dogs naturally infected by Leishmania infantum. Veterinary Record, v. 141, n. 21, p. 539-543, 1997.

COSTA, C. A. et al. Leishmaniose visceral canina: avaliação da metodologia sorológica utilizada em inquéritos epidemiológicos. Revista da Sociedade Brasileira de Medicina Tropical, v. 24, n. 1, p. 21-25, 1991.

COUTINHO, S. G. et al. A survey for American Cutaneous and Visceral Leishmaniasis among 1,342 dogs from areas in Rio de Janeiro (Brazil) 
where the human diseases occur. Memórias do Instituto Oswaldo Cruz, v. 80 , n. 1 , p. $17-22,1985$.

DEANE, L. M.; DEANE, M. P. Leishmaniose visceral urbana (no cão e no homem) em Sobral Ceará. O hospital, v. 47, p. 75-87, 1955.

FEITOSA, M. M. et al. Aspectos clínicos de cães com leishmaniose visceral no município de Araçatuba, São Paulo (Brasil). Clínica Veterinária, v. 5, n. 28, p. 36-44, 2000.

FERREIRA, E. C. et al. Comparison of serological assays for the diagnosis of canine visceral leishmaniasis in animals presenting different clinical manifestations. Veterinary Parasitology, v. 146, n. 3-4, p. 235-241, 2007.

FERRER, L. et al. Identification of Leishmania donovani amastigotes in canine tissues by immunoperoxidase stainning. Research in Veterinary Science, v. 44, n. 2, p. 194-196, 1988a.

FERRER, L. et al. Skin-lesions in canine leishmaniasis. Journal of Small Animal Practice, v. 29, n. 6, p. 381-388, 1988b.

GOMES, A. H. S. et al. PCR identification of Leishmania in diagnosis and control of canine leishmaniasis. Veterinary Parasitology, v. 144, n. 3-4, p. 234-241, 2007.

INSTITUTO BRASILEIRO DE GEOGRAFIA E ESTATÍSTICA IBGE. 2007. Disponível em: http://www.ibge.gov.br/home/.

LAINSON, R.; SHAW, J. J. Evolution, classification and geographical distribution. In: PETERS, W.; KILLICK-KENDRICK, R. The Leishmaniasis in biology and medicine. New York: Academic Press, 1987. p. 291-363. (v. 1, n. 1)

MACHADO, R. Z. et al. An enzyme-linked immunosorbent assay (ELISA) for the detection of antibodies against Babesia bovis in cattle. Veterinary Parasitology, v. 71, n. 1, p. 17-26, 1997.

MADEIRA, M. F. et al. Post mortem parasitological evaluation of dogs seroreactive for Leishmania from Rio de Janeiro, Brazil. Veterinary Parasitology, v. 138, n. 3-4, p. 366-370, 2006

MANNA, L. et al. Comparision of different tissue sampling for PCRbased diagnosis and follow-up of canine visceral leishmaniosis. Veterinary Parasitology, v. 125, n. 3-4, p. 251-262, 2004.

METTLER, M. et al. Evaluation of enzyme-linked immunosorbent assays, an immunofluorescent-antibody test, and two rapid tests (immunochromatographic-dipstick and gel tests) for serological diagnosis of symptomatic and asymptomatic Leishmania infections in dogs. Journal Clinical Microbiology, v. 43, n. 11, p. 5515-5519, 2005.

MOLINA, R. et al. Infectivity of dogs naturally infected with Leishmania infantum to colonized Phlebotomus perniciosus. Transactions of the Royal Society of Tropical Medicine and Hygiene, v. 88, n. 4, p. 491-493, 1994.

NOLI, C. Leishmaniosis canina. Waltham Focus, v. 9, n. 2, p. 16-24, 1999.

NUNES, C. M. et al. Avaliação da reação em cadeia pela polimerase para diagnóstico da leishmaniose visceral em sangue de cães. Revista Brasileira de Parasitologia Veterinária, v. 16, n. 1, p. 5-9, 2007.
OLIVEIRA, G. G. S.; SANTORO, F.; SADIGURSKY, M. The subclinical form of experimental visceral leishmaniasis in dogs. Memórias do Instituto Oswaldo Cruz, v. 88, n. 2, p. 243-248, 1993.

OLIVEIRA, T. M. F. S. et al. A study of cross-reactivity in serum samples from dogs positive for Leishmania sp, Babesia canis and Ehrlichia canis in enzyme-linked immunosorbent assay and indirect fluorescent antibody test. Revista Brasileira de Parasitologia Veterinária, v. 17, n. 1, p. 7-11, 2008.

PINELLI, E. et al. Cellular and humoral immune responses in dogs experimentally and naturally infected with Leishmania infantum. Infection and Immunity, v. 62, n. 1, p. 229-235, 1994.

REIS, A. B. et al. Parasite density and impaired biochemical hematological status areassociated with severe clinical aspects of canine visceral leishmaniasis. Research Veterinary Science, v. 81, n. 1, p. 68-75, 2006.

RODGERS, M. R.; POPPER, S. J.; WIRTH, D. F. Amplification of kinetoplast DNA as tool in the detection and diagnosis of Leishmania. Experimental Parasitology, v. 71, n. 3, p. 267-275, 1990.

ROSÁRIO, E. Y. et al. Evaluation of enzyme-linked immunosorbent assay using crude Leishmania and recombinant antigens as a diagnostic marker for canine visceral leishmaniasis. Memórias do Instituto Oswaldo Cruz, v. 100, n. 2, p. 197-203, 2005.

ROSS, R. Note on the bodies recently described by Leishman-Donovan and (2) Further notes on Leishman's bodies. British Medical Journal, v. 2, p. 1261-1401, 1903.

SANTA-ROSA, I. C. A.; OLIVEIRA, I. C. S. Leishmaniose Visceral: breve revisão sobre uma zoonose reemergente. Clínica Veterinária, v. 2, n. 11, 1997.

SIDERIS, V. et al. Asymptomatic canine leishmaniasis in Greater Athens area, Greece. European Journal of Epidemiology, v. 15, n. 3, p. 271-276, 1999.

SOLANO-GALLEGO, L. et al. Histological and immunohistochemical study of clinically normal skin of Leishmania infantum-infected dogs. Journal of Comparative Pathology, v. 130, n. 1, p. 7-12, 2004.

TAFURI, W. L. et al. An alternative immunohistochemical method for detecting Leishmania amastigotes in parafin-embedded canine tissues. Journal of Immunological Methods, v. 292, n. 1-2, p. 17-23, 2004.

TASCA, K. I. et al. Exames parasitológicos, imunoistoquímicos e histopatológicos para detecção de Leishmania chagasi em tecidos esplênicos de cães com leishmaniose visceral. Revista Brasileira de Parasitologia Veterinária, v. 18, n. 1, p. 27-33, 2009.

VEXENAT, A. C.; SANTANA, J. M.; TEIXEIRA, A. R. L. Crossreactivity of antibodies in human infections by the kinetoplastid protozoa Trypanosoma cruzi, Leishmania chagasi and Leishmania (Viannia) braziliensis. Revista do Instituto de Medicina Tropical de Sáo Paulo, v. 38, n. 3, p. 177-185, 1996. 